\title{
Abhandlungen
}

\section{International Law and the Internet}

\author{
Edited by Angelo Jr Golia, Matthias C. Kettemann and Raffaela Kunz
}

\section{Introduction}

by Matthias C. Kettemann, Raffaela Kunz and Angelo Jr Golia

Fifteen years is not a long time in the evolution of international law. Establishing the crystallisation of a rule into custom, for instance, might take decades. Fifteen years is, however, a substantial time when it comes to technological developments, especially information and communication technologies (ICTs). Probably the most important advancement in the field of ICTs is the evolution of the Internet into the key communication facility of our time. At its core, the Internet remains '[a] global computer network providing a variety of information and communication facilities, consisting of interconnected networks using standardised communication protocols'. ${ }^{1}$ But the Internet is more than such a technical definition might suggest. It has permeated all aspects of human life and human agency. It has substantially affected how states conduct international affairs, how threats are communicated and carried out, how information is gathered and spread, and, how attacks are prepared and made. International law questions abound, but the Internet also affects scholarly communication about international law and the way international legal scholarship is discussed and disseminated.

This is why we have put together this special issue on international law and the Internet. Ten contributions query into the role of international law for the Internet and the impact of the Internet on international law. Read together, they offer fascinating perspectives on international law as a force of order. International law already forms part of the normative infrastructure of the Internet, be it as a legal basis of the right to access to the internet, as a benchmark for assigning custodial sovereignty to a state with an important Internet Exchange Point (such as Germany's DE-CIX), as a yardstick for qualifying a state-led information operation via cyber channels as lawful (but awful) or unlawful, or for discussing the rights and duties of online platforms to delete hate speech. However, it remains an open question how interna-

1 Oxford English Dictionary, s. v. 'Internet' (2018), <https://en.oxforddictionaries.com>. 
tional law can successfully perform its role as the ius necessarium of the internet, with, next to, or even against the several forms of transnational private and/or hybrid regulation which continue to emerge.

The contributions in this special issue go a long way towards furthering this understanding. Rolf $\mathrm{H}$. Weber, who has been an influential voice in law of internet governance for the past decades, shows how the notion of Internet integrity can be usefully employed. Nula Frei discusses the role of equality in a world where all can be connected, but inequalities persist (and are exacerbated by differences in access to technology). Chien-Huei Wu focuses on the dark side of the 'cyber order' and identifies an authoritarian turn. Annalisa Ciampi shows how the Internet impacts the formation and evidence of custom and Antonio Segura-Serrano analyses the impact of international law on cybersecurity and describes new dynamics of norm development. Stefano Dominelli investigates the changing nature of diplomacy in times of digitalisation, as shows that foreign policy has to be rethought now that a lot of diplomatic action happens online. Applying concepts from space law and the law of the sea to cyberspace is often useful, as Patricia A. Vargas León, shows by reference to the Microsoft $v$. US case. Microsoft, as a big online company, is an important player in the digital ecosystem. With power also comes responsibility. As Christine Kaufmann shows, ensuring responsible business in a digital world is a case to be made on the basis of international law. Cäcilia Hermes then takes a step back and analyses cyberspace from the perspective of network theory. Concluding the special issue, Ralph Janik discusses how online platforms and the communication taking place on them have changed international legal discourse.

International Internet law develops quickly. We are therefore lucky to have among our authors one who has published already in 2006 - 15 years ago an analysis where he described international law not only as a 'tool for solving regulatory conflicts, but $[\ldots]$ a tool for governance' regarding key aspects of internet regulation, especially privacy, intellectual property, the use of force and human rights online, such as the right to internet access. ${ }^{2} \mathrm{He}$ called on international law to 'take a normative stance'. ${ }^{3}$ Since then, Antonio Segura-Serrano and others have developed international internet law much further - as he shows in his contribution on cybersecurity and norm development. More recently, authors have also analysed the reliance of internetrelated normative processes on non-traditional norms ${ }^{4}$ or criticised their

2 Antonio Segura-Serrano, 'Internet Regulation and the Role of International Law', Max Planck UNYB 10 (2006), 191-272 (192).

3 Segura-Serrano (n. 2), 271.

4 Martha Finnemore and Duncan B. Hollis, 'Constructing Norms for Global Cybersecurity’, AJIL 110 (2016), 425-479 (477) (emphasis added). 
prevalence, ${ }^{5}$ or developed a comprehensive 'normative order' 6 of the Internet, in which international law plays a key role as a normative anchor.

As the contributions collected here show, international law can act as an important retaining force in light of the ever quicker technological change. The goal is clear. After all, the international community committed itself to achieving a 'people-centred, inclusive and development-oriented Information Society [...] premised on the purposes and principles of the Charter of the United Nations and respecting fully and upholding the Universal Declaration of Human Rights(.)' We hope that this special issue will further stimulate this important debate that even after fifteen year is certainly far from being over.

Last but not least, it is worth mentioning that this special issue has been edited during (and despite) the troubled period that started with the outbreak of the COVID-19 pandemic in 2020. It collects a selection of the papers presented at the authors' workshop held online on 15-16 October 2020. In the following months, reviewing and editing the papers has been particularly challenging and would not have been possible without the generous contribution of several people. Here, we would like to particularly thank the anonymous reviewers, Andrea Hug from the Redaktion of the ZaöRV, and the student assistants that helped us, especially Elisabeth Alexander, Sarah Gebel, Carolin Eschenfelder, Leon Seidl, Marieke Simons.

5 Calling on states to develop a treaty-based international law of cybersecurity: Kubo Mačák, 'From Cyber Norms to Cyber Rules: Re-engaging States as Law-makers', LJIL 30 (2017), 877-899.

6 Matthias C. Kettemann, The Normative Order of the Internet (Oxford: Oxford University Press 2020). 
